\title{
Paraneoplastic neurological syndromes associated with ovarian tumors
}

\author{
Mikolaj Piotr Zaborowski • Marek Spaczynski • \\ Ewa Nowak-Markwitz $\cdot$ Slawomir Michalak
}

Received: 4 April 2014 / Accepted: 10 June 2014 / Published online: 26 June 2014

(C) The Author(s) 2014. This article is published with open access at Springerlink.com

\begin{abstract}
Introduction Paraneoplastic neurological syndromes (PNS) are neurologic deficits triggered by an underlying remote tumor. PNS can antedate clinical manifestation of ovarian malignancy and enable its diagnosis at an early stage. Interestingly, neoplasms associated with PNS are less advanced and metastasize less commonly than those without PNS. This suggests that PNS may be associated with a naturally occurring antitumor response.

Methods We review the literature on the diagnosis, pathogenesis and management of PNS associated with ovarian tumors: paraneoplastic cerebellar degeneration (PCD) and anti- $N$-methyl-D-aspartate receptor (anti-NMDAR) encephalitis. An approach to the diagnostic workup of underlying tumors is discussed.

Results PCD can precede the manifestation of ovarian carcinoma. Anti-NMDAR encephalitis in young women
\end{abstract}

M. P. Zaborowski · M. Spaczynski · E. Nowak-Markwitz Division of Gynecologic Oncology, Department of Gynecology, Obstetrics and Gynecologic Oncology, Poznan University of Medical Sciences, Polna str. 33, 60-535 Poznan, Poland e-mail: mikolaj.zaborowski@gmail.com

Present Address:

M. P. Zaborowski

Department of Neurology, Massachusetts General Hospital, Harvard Medical School, Boston, MA 02129, USA

S. Michalak $(\bowtie)$

Department of Neurochemistry and Neuropathology, Poznan University of Medical Sciences,

Przybyszewskiego str. 49, 60-355 Poznan, Poland

e-mail: swami622@gmail.com

S. Michalak

Neuroimmunological Unit, Polish Academy of Sciences,

Przybyszewskiego str. 49, 60-355 Poznan, Poland appears often as a result of ovarian teratoma. Since ovarian tumors and nervous tissue share common antigens (e.g., cdr2, NMDAR), autoimmune etiology is a probable mechanism of these neurologic disorders. The concept of cross-presentation, however, seems insufficient to explain entirely the emergence of PNS. Early resection of ovarian tumors is a significant part of PNS management and improves the outcome.

Conclusions The diagnosis of PNS potentially associated with ovarian tumor indicates a need for a thorough diagnostic procedure in search of the neoplasm. In some patients, explorative laparoscopy/laparotomy can be considered.

Keywords Ovarian cancer - Ovarian teratoma · Paraneoplastic cerebellar degeneration · Anti-NMDAR encephalitis

\section{Key points}

- PNS precede clinical manifestation of ovarian tumors and enable their diagnosis at an early stage.

- Paraneoplastic cerebellar degeneration (PCD) can coexist with ovarian carcinoma.

- Anti-NMDAR antibodies detected in patient affected with encephalitis are highly suggestive of ovarian teratoma.

- Ovarian tumors and nervous tissue share common antigens in PNS (e.g., cdr2, NMDA receptor) - the concept of cross-presentation, however, may not be sufficient to explain an emergence of PNS.

- Cell-mediated immune response plays a role in the pathogenesis of PNS.

- Antibody-mediated immune response is a major mechanism of anti-NMDAR encephalitis and other NSAS. 
- In patients with PNS associated potentially with ovarian tumors, transvaginal ultrasound examination and pelvic CT scan are indicated-if negative, PET imaging is required.

- If imaging studies remain normal, explorative laparoscopy/laparotomy should be considered.

- An early resection of ovarian tumors is a significant part of PNS management and improves the outcome.

\section{Definition}

Paraneoplastic neurological syndromes (PNS) are defined as the pathologic involvement of the nervous system in the course of malignancy. This entity does not include tumor infiltration, compression or metastasis of the nervous system (Graus et al. 2004). PNS often precede clinical manifestation of a tumor and enable diagnosis at an early stage. Interestingly, neoplasms that appear in patients with PNS are limited in size and metastasize less commonly than those without PNS (Hetzel et al. 1990; Albert and Darnell 2004). These observations suggest that PNS provide an example of a naturally occurring antitumor response. Ovarian tumors account for about $10 \%$ of malignancies associated with PNS (Giometto et al. 2010). Paraneoplastic cerebellar degeneration (PCD), the most common paraneoplastic neurological syndrome, may coexist with ovarian carcinoma (Giometto et al. 2010). Recently, a group of neurologic disorders, neuronal surface antibodies syndromes (NSAS), has been defined (Zuliani et al. 2012). They usually affect the central nervous system in the form of encephalitis that manifests mainly as behavioral disorder and seizures. However, they are rarely related to malignancy. One of NSAS, however, anti-NMDAR encephalitis, appears typically in young women with a benign tumor, ovarian teratoma.

The diagnosis of PNS is based on criteria defined in Graus et al. (2004). This takes into account neurological symptoms, presence of a tumor and antibodies associated with this condition, referred to as onconeural antibodies (Graus et al. 2004). The diagnosis of PNS is a complex process that always requires exclusion of primary etiology of neurologic symptoms, including among others-vascular disorders, infection, nervous tissue tumors or hereditary syndromes. The classification of PNS distinguishes "classical syndromes" and "well-characterized onconeural antibodies" that are the most specific for PNS (Tables 1,2). The term "definite PNS" in contrast to "possible PNS" indicates higher probability of the paraneoplastic nature of a disorder (Table 3). This differentiation is important since definite PNS requires a more intense search for underlying tumor. Neuronal surface antibodies syndromes typically
Table 1 Classical paraneoplastic syndromes

Classical paraneoplastic neurological syndromes

Encephalomyelitis

Limbic encephalitis

Subacute cerebellar degeneration

Opsoclonus-myoclonus

Subacute sensory neuronopathy

Chronic gastrointestinal pseudo-obstruction

Lambert-Eaton myasthenic syndrome

Dermatomyositis

PNS the most commonly associated with ovarian tumors are in bold (Graus et al. 2004)

respond well to immunotherapy. Hence, once the diagnosis of anti-NMDAR encephalitis is established, it is classified as "definite NSAS" if it is responsive to immunomodulatory agents such as steroid and intravenous immunoglobulin and as "probable NSAS" if not responsive (Zuliani et al. 2012).

\section{Incidence}

Paraneoplastic syndromes are rare in cancer patients. In the group of 1,465 unselected patients with various tumors, the history and physical examination revealed neurologic abnormalities in 96 individuals (Croft and Wilkinson 1965). In 55 women with ovarian cancer, neurologic disorder was diagnosed in nine patients (Croft and Wilkinson 1965). These data should, however, be interpreted with caution as since the time this study was performed the diagnostic criteria of PNS have evolved markedly. It is estimated that paraneoplastic neurological syndromes appear in about $1 \%$ of all malignancies (Rees 2004). The diagnosis, however, becomes more probable in particular contexts-approximately half of patients with non-familial cerebellar syndrome of subacute onset suffer from some malignancy, primarily ovarian or lung cancer. The criteria for NSAS diagnosis were clearly defined in 2012 (Zuliani et al. 2012). Antibodies in anti-NMDAR encephalitis typically associated with ovarian teratoma were described for the first time in 2005 (Vitaliani et al. 2005). In over 3 years, more than 400 cases of NSAS have been reported (Dalmau et al. 2011). This entity can affect adolescents and children, as well as adults. It is worth mentioning that three cases of anti-NMDAR encephalitis occurred during pregnancy complicated with ovarian teratoma (Kumar et al. 2010). Though PNS are still considered rare, their estimates of incidence increase with the improvement in diagnostic tools. 
Table 2 Onconeural and neuronal surface antibodies

\begin{tabular}{lll}
\hline \multicolumn{2}{l}{ Onconeural and neuronal surface antibodies } \\
\hline Well characterized & $\begin{array}{l}\text { Partly character- Neuronal surface antibodies } \\
\text { ized }\end{array}$ \\
\hline Anti-Hu & Anti-Tr & Anti-VGKC complex antigens \\
Anti-Yo & Anti-Zic4 & (LGI1 or CASPR2) \\
Anti-Ri & Anti-mGluR1 & Anti-NMDAR \\
Anti-CV2 & ANNA3 & Anti-AMPAR \\
Anti-Ma & PCA2 & Anti-GABABR \\
Anti-amphiphysin & & Anti-GlyR \\
& & Anti-VGCC-Ab \\
& & Anti-mGluR1 \\
& & Anti-mGluR5 \\
\hline
\end{tabular}

Antibodies detected commonly in PNS associated with ovarian tumors are in bold (Graus et al. 2004; Titulaer et al. 2011; Zuliani et al. 2012)

\section{Diagnosis}

Paraneoplastic neurological syndromes may be diagnosed prior to tumor detection. It is worth stressing that a combination of classical PNS and the detection of well-characterized antibodies are known to be involved in PNS, even without established diagnosis of malignancy is also referred to as definite paraneoplastic disorder (Table 3). In such cases, there is an obligation to screen for underlying malignancy (Titulaer et al. 2011). In a group of 55 patients with PCD the neurological symptoms antedated the diagnosis of a neoplasm in 34 individuals (Peterson et al. 1992). In 18 out of 19 women with gynecologic cancer, primarily ovarian carcinoma, neurologic pathology preceded the detection of malignancy (Hetzel et al. 1990). The time between the onset of paraneoplastic syndrome and diagnosis of a tumor varies from a few weeks to months or even years (Hetzel et al. 1990; Rojas et al. 2000). Thus, PNS symptoms enable detection of a neoplasm at a very early stage. Rarely, paraneoplastic neurological syndrome may emerge after completed treatment of ovarian cancer (Forgy et al. 2001; Goldstein et al. 2009; Russo et al. 2013). Unfortunately, the paraneoplastic reaction is sometimes so intense that it itself worsens significantly the patient's clinical outcome and leads to disability (Cao et al. 1999). Paraneoplastic cerebellar syndromes are highly debilitating and often irreversible (Mason et al. 1997). By contrast, anti-NMDAR encephalitis that affects women with ovarian teratoma responds well to tumor resection and subsequent immunotherapy which may lead to almost complete recovery.

\section{Clinical presentation}

The onset of signs and symptoms of paraneoplastic syndrome is usually subacute and develops within a few weeks. PCD manifests clinically as cerebellar syndrome. The patient suffers from incoordination of movements (ataxia), balance and gait disturbances, speech disorder (dysarthria) and altered ocular movements (nystagmus, often in a downbeat form) (Peterson et al. 1992; Dalmau and Rosenfeld 2008). Paraneoplastic neurological syndromes associated with ovarian tumors may also appear as a peripheral polyneuropathy with diffuse paresthesia and anesthesia (Cao et al. 1999). Young women or children with ovarian teratoma can be affected with encephalitis that manifests as psychosis, memory loss and behavior disorder. It subsequently develops into seizures, dyskinesias and autonomic instability (Florance et al. 2009; Tanyi et al. 2012; Zuliani et al. 2012). Neurologic pathology is often highly debilitating and renders many patients either wheelchair bound or bedridden (Frings et al. 2005).

Table 3 Definite and possible PNS according to diagnostic criteria as published by Graus et al. (2004)

\begin{tabular}{lc}
\hline Definite PNS & Possible PNS \\
\hline $\begin{array}{l}\text { Definite and possible diagnosis of PNS } \\
\text { 1. A classical syndrome and cancer that develop within 5 years of the } \\
\text { diagnosis of the neurological disorder }\end{array}$ & $\begin{array}{c}\text { 1. A classical syndrome, no onconeural antibodies, no cancer is diag- } \\
\text { nosed, but at high risk for having an underlying tumor }\end{array}$ \\
$\begin{array}{l}\text { 2. A non-classical syndrome that resolves or significantly improves } \\
\text { after cancer treatment without concomitant immunotherapy provided } \\
\text { that the syndrome is not susceptible to spontaneous remission }\end{array}$ & $\begin{array}{c}\text { 2. A neurological syndrome (classical or not) with partially character- } \\
\text { ized onconeural antibodies and no cancer }\end{array}$ \\
$\begin{array}{l}\text { 3. A non-classical syndrome with onconeural antibodies (well charac- } \\
\text { terized or not) and cancer that develops within } 5 \text { years of the diagno- }\end{array}$ & $\begin{array}{c}\text { 3. A non-classical syndrome, no onconeural antibodies and cancer } \\
\text { present within 2 years of diagnosis }\end{array}$ \\
$\begin{array}{l}\text { sis of the neurological disorder } \\
\text { 4. A neurological syndrome (classical or not) with well-charac- } \\
\text { terized onconeural antibodies (anti-Hu, Yo, CV2, Ri, Ma2 or }\end{array}$ & \\
amphiphysin) and no cancer &
\end{tabular}

Neurological syndrome with well-characterized antibodies (in bold) is a clinical setting that requires intense search for underlying malignancy and often enables its detection at an early stage. Reproduced from 'Recommended diagnostic criteria for paraneoplastic neurological syndromes' (Graus et al. 2004) with permission from BMJ Publishing Group Ltd. 


\section{Antibodies}

Laboratory analyzes may reveal the presence of onconeuronal antibodies. They are detected by means of an indirect immunofluorescence and confirmatory Western or line blot (Monstad et al. 2008; Stefens-Stawna et al. 2013). The most common type of antibody found in PCD is anti-cdr2 (cerebellar degeneration protein-2 antibody) (also known as antiYo) (Anderson et al. 1988; Peterson et al. 1992). Anti-Yo antibody seropositive status suggests ovarian cancer, breast cancer or other gynecologic malignancies (Peterson et al. 1992). Infrequently, it can be related to small cell lung cancer (Greenlee and Lipton 1986). Recently, new antibodies, termed anti-cdr2-like (cdr2L), have been described (Eichler et al. 2013). They are reactive against an antigen similar to the cdr2 protein, which instead of being cytoplasmic is within the cell membrane. The coexistence of antibodies to cdr2 and cdr2L is strongly suggestive of definite PNS. Surprisingly, PCD has been diagnosed only in patients with both antibodies. Paraneoplastic cerebellar syndrome may also be associated with anti-Hu antibodies which raises suspicion of small cell lung cancer. The detection of anti$\mathrm{Ri}$, in turn, suggests an underlying breast cancer. Clinician should also take into consideration the diagnosis of lymphoma, especially if anti-Tr or anti-mGluR1 antibodies are identified (Shams'ili et al. 2003). Interestingly, PCD related to anti-Yo antibodies is associated with a worse survival due to cancer as compared to other antibodies (Giometto et al. 2010). In a group of neuronal surface antibodies syndromes, anti-NMDAR antibodies are strongly indicative of ovarian teratoma (Florance et al. 2009; Zuliani et al. 2012). A substantial number of patients, however, manifest paraneoplastic syndromes unrelated to detection of any of the above antibodies (Giometto et al. 2010). In addition, onconeuronal antibodies appear in some patients with ovarian tumors who do not suffer from any neurological symptoms. In a group of 181 women with ovarian cancer without paraneoplastic syndrome, there were four who had anti-Yo and seven who had anti-Ri onconeuronal antibodies (Drlicek et al. 1997). The detection of anti-cdr2 antibodies in ovarian cancer can be improved by in vitro transcription-translation (ITT) of radiolabelled cdr2 protein and immunoprecipitation assay (Monstad et al. 2006; Eichler et al. 2013). Anti-NMDAR antibodies were detected in six out 21 women with teratoma (Michalak et al. 2010). In another study, however, anti-NMDAR antibodies were not found among 20 neurologically asymptomatic patients with ovarian teratoma (Mangler et al. 2013). In general, ovarian tumors have high potential to mount an immune response, since anti-ovarian autoantibodies are commonly found in patients affected with these neoplasms (Szubert et al. 2012). The detection of antibodies is a major reason to raise the suspicion of paraneoplastic syndrome in a patient who manifests neurologic symptoms. The type of antibody indicates the most probable tumor location, including ovarian cancer and ovarian teratoma.

\section{CSF analysis}

An analysis of cerebrospinal fluid (CSF) may display pleocytosis (with a high fraction of lymphocytes), elevated protein or oligoclonal bands (Frings et al. 2005; Rubello et al. 2005; Tanyi et al. 2012). Inflammatory changes and antiNMDAR antibodies in CSF are frequently present in antiNMDAR encephalitis (Vitaliani et al. 2005; Dalmau et al. 2011). In some patients with PCD, however, no abnormalities have been detected in the CSF (Peterson et al. 1992). Though the analysis of CSF often reveals disturbances in PNS, it is more informative in anti-NMDAR encephalitis than in PCD.

\section{Imaging studies}

Magnetic resonance imaging (MRI) in PCD can reveal cerebellar atrophy (Frings et al. 2005). This is consistent with pathological postmortem examination, which demonstrates significant loss of Purkinje cells and sometimes coexistent infiltrates within cerebellum. In some PCD patients, however, both MRI and CT scan can appear normal (Negishi et al. 2013). The fluorodeoxyglucose positron-emission tomography (FDG-PET), in turn, imaging most commonly reveals cerebellar hypometabolism in PCD (Basu and Alavi 2008). Rarely, increased FDG uptake, consistent with hypermetabolism, is found in the cerebellar region (Choi et al. 2006). Imaging studies are useful mainly for differential diagnosis of cerebellar disorders. They help to exclude other conditions related to neoplasm that may give rise to neurologic symptoms, such as metastases, infiltration or vascular complications. MRI in anti-NMDR encephalitis in $50 \%$ of patients shows hyperintensity in various brain regions, including hippocampus, corpus callosum, temporal and frontal lobes, while in other patients the brain image appears normal (Dalmau et al. 2011; Tanyi et al. 2012). Though imaging studies are not key to establish the diagnosis of PNS so far, they are indispensable in excluding other conditions responsible for neurologic symptoms.

\section{Electroencephalogram (EEG)}

The EEG is pathological in the majority of patients with anti-NMDAR encephalitis. Abnormally slow and disorganized activity is usually not associated with anomalous movements and is unresponsive to antiepileptic therapy (Dalmau et al. 2008, 2011). It is consistent with a diffuse affection of brain tissue associated with encephalitis. 


\section{Ovarian tumors}

PNS can provide an opportunity to investigate naturally occurring antitumor immunity (Albert and Darnell 2004). In $\mathrm{Hu}$ syndrome associated with small cell lung cancer, the beneficial effect on survival of early detection due to PNS symptoms is well proven and several cases of tumor regression have been reported (Darnell and DeAngelis 1993; Graus et al. 1997). It is a question of debate, however, whether such a phenomenon applies to all tumors, including ovarian cancer. Specific cytotoxic T lymphocytes active against cdr2 antigen expressed by ovarian cancer and Purkinje cells were identified in peripheral blood in patients with PCD (Albert et al. 1998). In some patients with ovarian cancer coexisting with PCD, tumors are limited in size and only discovered by microscopic examination (Peterson et al. 1992) and have fewer secondary foci in comparison with patients without PCD (Hetzel et al. 1990). By histopathological analysis, these tumors are characterized as lesion with intense lymphocyte infiltration characteristic of an immune response (Peterson et al. 1992; Cao et al. 1999). On the other hand, in another study, metastatic disease was discovered in 15 out of 18 patients with ovarian cancer and PCD, with a median survival of 22 months comparable to patients with this form of cancer without PCD (Rojas et al. 2000). However, it can be hard to estimate an effect of antitumor response on overall survival as nearly half of the patients with PNS die from neurologic pathology (Rojas et al. 2000). Currently, in PCD associated with ovarian cancer, there is no study that explicitly corroborates an effective antitumor response in terms of prognosis. Further, the presence of anti-Yo antibodies in neurologically normal patients with ovarian cancer had no influence on survival (Drlicek et al. 1997). Hence, the antitumor reaction is probably effective at the very beginning of tumor development, so it less advanced at the time of diagnosis. For unknown reason, this response fails to eliminate cancer cells and the tumor progresses in a natural aggressive way. The nature of antitumor reaction in ovarian cancer coexistent with PCD requires more research.

Ovarian tumors associated with anti-NMDAR encephalitis include mainly teratomas (Dalmau et al. 2007, 2011). Among 91 women with anti-NMDAR encephalitis, 49 had ovarian teratoma, including 17 immature tumors and eight bilateral ovarian lesions (Dalmau et al. 2008). Cases of sex cord-stromal tumors coexistent with anti-NMDAR encephalitis were also reported (Tanyi et al. 2012). Pathological studies revealed the presence of nervous tissue with the expression of NR2 subunit of NMDA receptor within all teratomas (Dalmau et al. 2007, 2008). Significant inflammatory infiltrates were also demonstrated in tumors associated with anti-NMDAR encephalitis (Tüzün et al. 2009). The strong link between anti-NMDAR encephalitis and ovarian teratomas incidence can be well explained by the cross-presentation of the same antigen.

\section{Pathogenesis}

Autoimmune processes undoubtedly take part in pathogenesis of PNS (Darnell and Posner 2003). The major hypothesis about the origins of PNS states that tumors express antigens that are normally present almost exclusively in nervous tissue (Fig. 1). The presentation of neuronal antigens by a neoplasm then mounts an intense immune response against the tumor which cross-reacts with the nervous tissue. To study this hypothesis, investigators have searched for onconeuronal antigens common to both nervous tissue and ovarian tumors. Sera of patients affected with PCD were incubated with ovarian cancer tissue from individuals without neurologic pathology (Darnell et al. 2000). In 13 out of 20 tissues, an antigen cdr2 (also called Yo protein) was detected in both cerebellar neurons and ovarian tumors. This cdr2 antigen was also expressed in 2 out of 9 breast cancer specimens as well. In one study, the protein was found in a normal ovary (Totland et al. 2011). It appears that many ovarian cancers express this protein, irrespective of the presence of anti-Yo antibodies or manifestation of PCD in patients (Darnell et al. 2000; Totland et al. 2011). The same relationship was observed in paraneoplastic neurological syndromes that accompany other malignancies, for example, with all small cell lung cancers possessing the $\mathrm{Hu}$ antigen and only some patients developing paraneoplastic Hu syndrome (Manley et al. 1995). Thus, the presence of onconeuronal antigens and antibodies against them does not completely correlate with the origin of paraneoplastic reaction.

A detection of onconeuronal antibodies is important for the syndrome diagnosis, even though it is not compulsory according to diagnostic criteria (Graus et al. 2004). The importance of this humoral response in the pathomechanism of the disease, however, is unclear. The passive transfer of antibodies to onconeuronal antigens did not lead to neurologic pathology in mouse model (Tanaka et al. 1995). Further, immunization of mice with human cdr2 antigen induced only antibody production in the absence of nervous tissue damage (Tanaka et al. 1994, 1995). It appears that lymphocytes taken from patients' blood samples were also active against the same antigens as antibodies used in diagnosis (Albert et al. 1998; Tanaka et al. 1998; Albert et al. 2000; Zaborowski and Michalak 2013). Specific cytotoxic T lymphocytes have been found both in acute and chronic phase of PCD. In PCD associated with the anti-Yo antibody, a high frequency of HLA A24 has been demonstrated (Tanaka and Tanaka 1996). This observation suggests that patients in this group are 


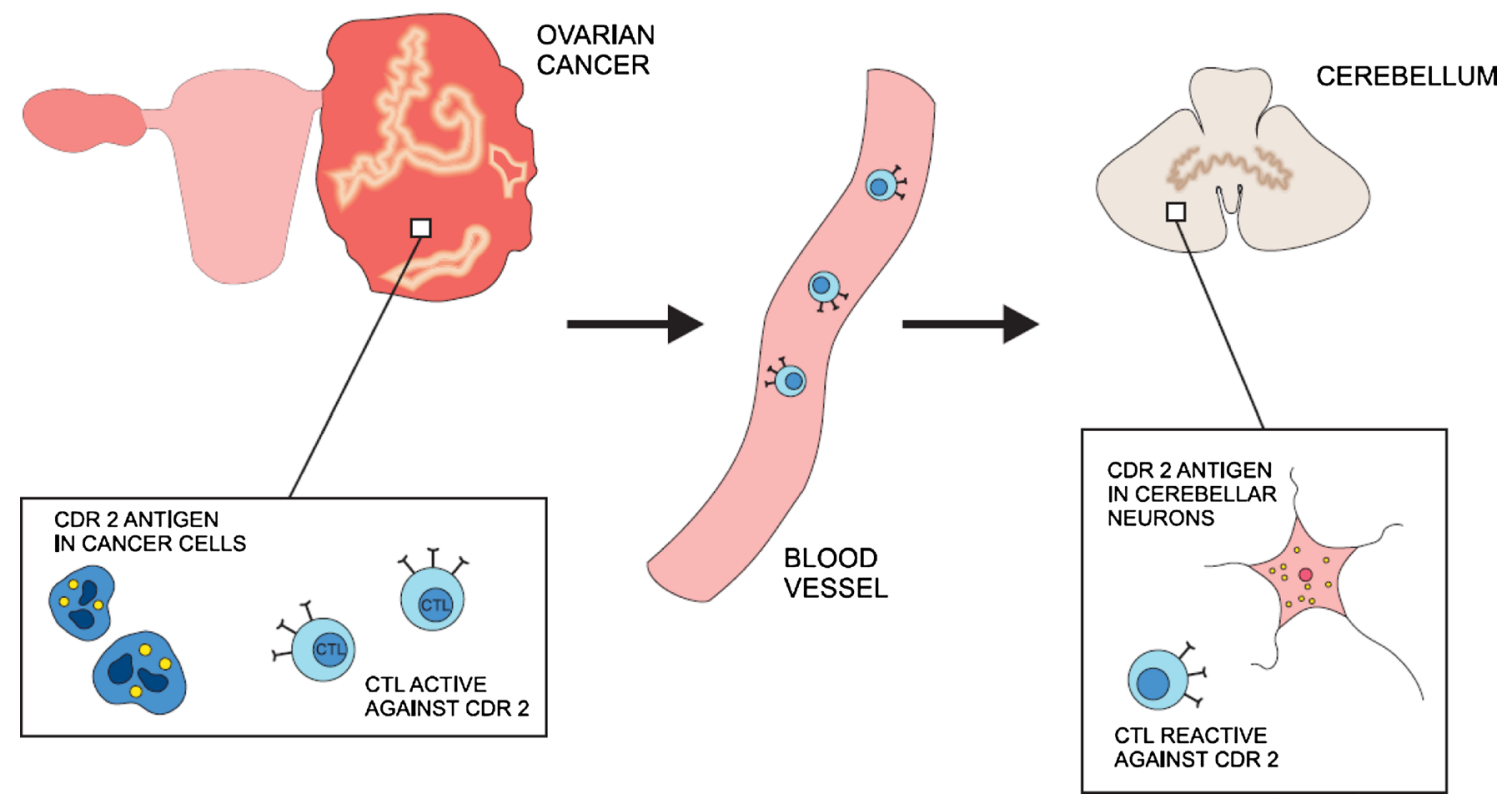

Fig. 1 Ovarian cancer cell expresses cdr 2 antigen that triggers immune response against malignancy. The same cdr2 antigen is a intracellular protein in Purkinje cell in cerebellum. As a result, cytotoxic $\mathrm{T}$ lymphocytes (CTL) cross-react against nervous tissue. This

more susceptible to autoimmune disorder, which is consistent with the involvement of cytotoxic $\mathrm{T}$ lymphocytes. It seems, on the other hand, that cell-mediated reaction is not always involved in neuronal damage in the course of PNS, as pathology studies do not always reveal infiltrates that accompany significant neuronal loss (Peterson et al. 1992) and a number of patients with PCD lack antibodies to onconeuronal antigens (Anderson et al. 1988). In rat models of neoplastic disease, cerebellar degeneration with Purkinje cell loss has been described without any detectable onconeuronal antibodies (Michalak 2008). The recent identification of anti-cdr2L antibodies may shed new light on the mechanism involved in PCD emergence (Eichler et al. 2013), and other, as yet unidentified, onconeural antigens may still be discovered. In contrast to the cdr2 protein that is cytoplasmic, cdr2L antigen is present at the cell membrane which may make it more accessible for antibody-mediated cytotoxicity. Moreover, when both present, anti-cdr2 and anti-cdr2L antibodies had much higher avidity than when detected alone. It was consistent with the fact that only patients with both antibody types developed definite PNS in contrast to individuals with either anti-cdr2 or anti-cdr2L alone. Cdr2L antigen is expressed both in Purkinje cells in cerebellum and in ovarian tumor tissue. The role of anti-cdr2L in the mechanism of PCD certainly requires further exploration. Taken together, the immune reaction, especially cell-mediated response, is an important player in the origins of PCD. Contradictory results of research in animal models, however, suggest that mechanism represents the prevailing view on the pathogenesis of paraneoplastic cerebellar degeneration (PCD) related to ovarian cancer. The hallmarks of immune reaction, however, are not detected in all patients

other factors potentially deleterious to nervous tissue may also be involved.

Cdr2 is involved in the inhibition of c-myc oncoprotein that is widely expressed in many tumors, including ovarian cancer (Okano et al. 1999). Cdr2 sequesters c-myc and prevents it from inducing transcription. Cdr2 expression presumably represses cell proliferation through this mechanism, functioning as a tumor suppressor. Elevated expression of $\operatorname{cdr} 2$ in a tumor tissue may lead to immune responses that are also active against nervous tissue. Overexpression of cdr2 could explain why PCD appears in neoplasms that have a less aggressive course, since suppressive mechanisms mediated by cdr2 are constitutively more effective. Since in PNS, tumors have often intense infiltrates and the significance of cell-mediated immune response has been revealed, it is probable that immune responses eliminate cancer cells.

By contrast, the pathogenic role of antibodies seems well proven in anti-NMDAR encephalitis (Fig. 2). In vitro studies revealed that rat neurons incubated with patients' sera containing anti-NMDAR antibodies had reduced numbers of NMDA receptors in postsynaptic dendrites. This phenomenon was reversible after treatment with control CSF (Dalmau et al. 2008). Moreover, in antiNMDAR encephalitis, clinical improvement is associated with a decrease in NMDR antibody titers (Dalmau et al. 2008). Pathological studies have demonstrated numerous antibody deposits and scarce cell infiltrates in affected regions of brain (Tüzün et al. 2009). Notably, the NMDR 


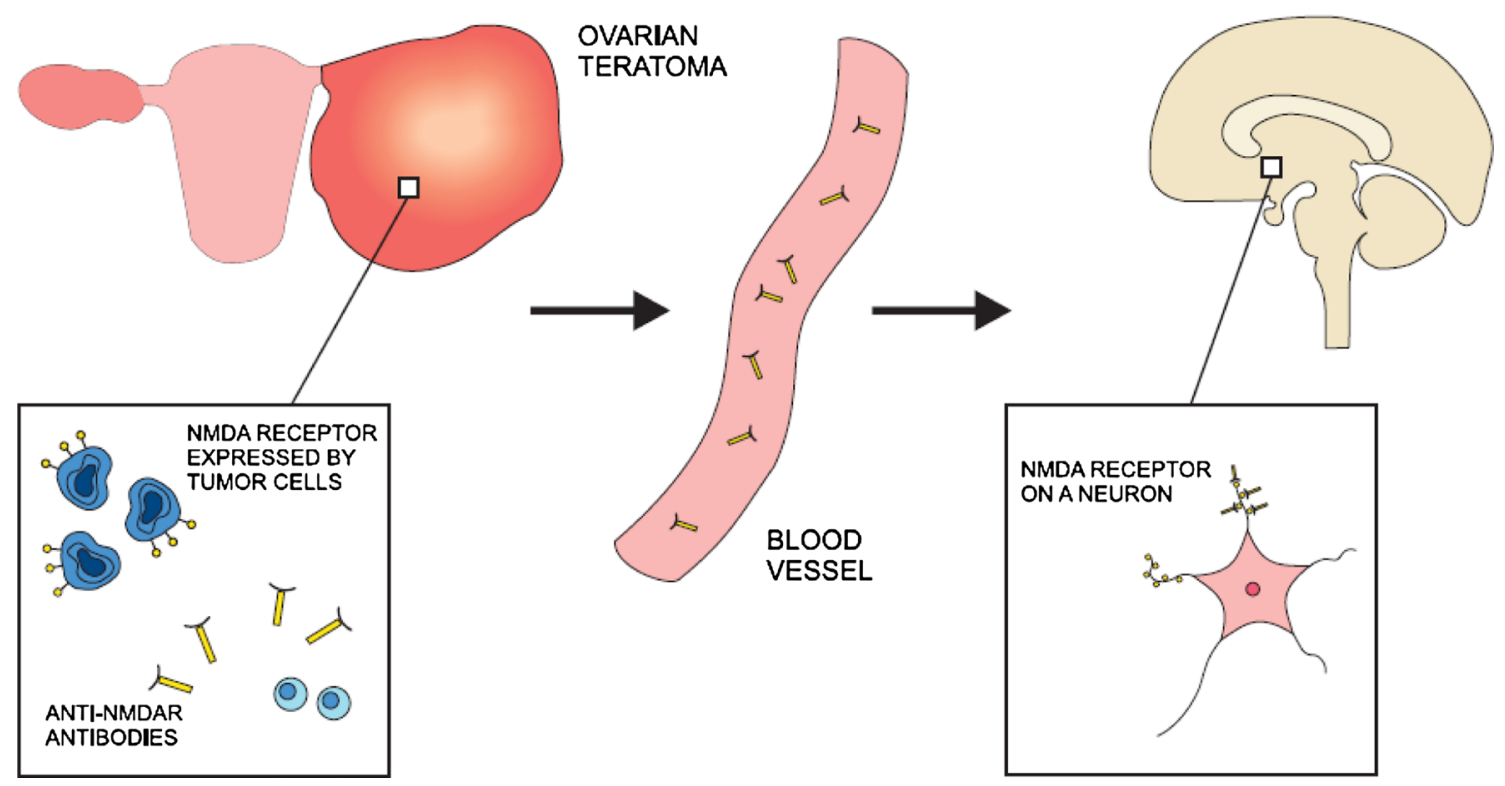

Fig. 2 NMDA receptor (NMDAR) is expressed on the surface of ovarian teratoma cells. As a result of immune reaction, anti-NNMAR antibodies are produced. The same receptor is present at the dendrites of neurons in many region of central nervous system. Anti-NMDAR

antigens for these antibodies were identified mainly in hippocampus (Vitaliani et al. 2005). In contrast to intracellular onconeuronal antigens, the target protein was detected within the plasma membrane which makes it more accessible to antibodies. A favorable clinical response to plasma exchange also provides an argument in favor of antibody-mediated mechanism of disease. NMDAR antigen has been found in all ovarian teratomas excised in the course of anti-NMDAR encephalitis (Tüzün et al. 2009). These observations suggest that the cross-presentation of NMDAR antigen in neurons and ovarian tumor leads to the anti-NMDAR antibodies production, which induces encephalitis.

\section{Management}

Diagnosis of PCD should always be associated with a search for a primary origin of malignancy. This nervous system pathology is most commonly seen in ovarian, breast and small cell lung cancers or lymphoma (Peterson et al. 1992). In some patients, an ovarian tumor can be visualized by transvaginal ultrasound or by pelvic CT scan (Negishi et al. 2013). The neoplastic disease, however, is frequently at a very early stage and consequently a conventional diagnostic procedure may appear inconclusive. A number of studies show that the use of FDG-PET imaging is more sensitive and justified in this clinical context (Frings et al. 2005). An ovarian tumor that was not visible in transvaginal antibodies enter nervous tissue through the vasculature and react against the target protein. Consequently, neural signaling mediated by NMDA receptor is considerably disturbed leading to both psychiatric and neurologic symptoms

ultrasound appeared evident on the integrated PET-CT scan (Marchand et al. 2007). Surgery confirmed the diagnosis of a papillar serous adenocarcinoma of an ovary at stage IIB. An annual follow-up of another patient with PCD uncovered hyperactivity of an axillary region 5 years after the onset of neurologic symptoms (Mathew et al. 2006). The biopsy was consistent with metastasis of breast cancer. In some patients, combined FDG-PET imaging is the only one that can reveal the location of the malignancy (Rubello et al. 2005).

It is rather the antigenic specificity than particular neurologic syndromes that is more indicative for tumor location (Titulaer et al. 2011). The most specific for diagnosis, however, is the combination of both. In patients with antiYo, anti-Ri or anti-amphiphysin antibodies ovarian cancer should be suspected. If anti-NMDAR antibody is detected, it suggests coexistence of teratoma, including its immature type. The metanalysis of numerous studies conducted by Titulaer et al. (2011) contains conclusions concerning management. In all these patients, transvaginal ultrasound is the investigation of choice. If it is negative, pelvic computed tomography or magnetic resonance imaging should be performed. In patients with antibodies that suggest ovarian cancer, an integrated FDG-PET/CT is indicated. It is important to perform it as soon as possible as combined PET/CT scan used in this context may significantly reduce the delay time to the surgery (Frings et al. 2005). If initial investigations do not detect any tumor, it is recommended to repeat them every 6 months for 4 years. 
PNS develop as a result of the malignancy. Thus, it is not surprising that the neurological outcome in PCD may improve after tumor excision. Subsequent systemic immune therapy in the form of intravenous immunoglobulin, steroids and tacrolimus has also proven beneficial (Negishi et al. 2013). In young women affected with NMDR encephalitis associated with teratoma, surgical removal of the tumor in combination with plasma exchange, steroid and intravenous immunoglobulin may yield almost complete recovery (Tanyi et al. 2012). In some patients, a second-line immunotherapy (rituximab or cyclophosphamide) is necessary (Dalmau et al. 2011). It has been proven that early surgery combined with immunotherapy markedly improves outcome (Dalmau et al. 2008).

The question arises whether the diagnosis of paraneoplastic reaction commonly associated with ovarian tumor may itself constitute an indication for surgical management. Exhaustive laboratory and imaging investigations often remain inconclusive as to the presence and location of the tumor. Some reports suggest, however, that explorative surgery may reveal an occult neoplasm. In a group of 19 patients with both ovarian cancer and paraneoplastic cerebellar syndrome, laparotomy was performed (Hetzel et al. 1990). In seven women, there were no tumor symptoms and the laboratory as well as imaging investigation was normal prior to the surgery. The decision on operative management was taken exclusively based on the detection of onconeuronal antibodies. Surprisingly, all these patients had highgrade ovarian adenocarcinoma. Another remarkable observation made by the authors was either the lack of or limited volume of peritoneal invasion that are typical for advance ovarian cancer. In another study, laparotomy performed in some patients with PCD uncovered solely microscopic foci of ovarian cancer (Peterson et al. 1992). These findings are consistent with a report of postmortem examination of a patient who died due to very severe paraneoplastic reaction affecting the nervous system (BRAIN et al. 1951). It revealed two very small ovarian tumors the size of which did not exceed $2 \mathrm{~cm}$ in diameter. These phenomena suggest that paraneoplastic reaction corresponds to an antitumor response. The history of a patient with PCD and abnormal CA-125 levels at postmenopausal age has also been reported (Mason et al. 1997). Though imaging studies did not suggest ovarian pathology, both laparoscopic salpingooophorectomy and endometrial biopsy were performed. The pathological examination did not confirm malignancy; however, the CA-125 level decreased to normal limits after ovarian resection. Another report presented the history of a patient with PCD whose retroperitoneal lymph node was enlarged to the size of $2.2 \mathrm{~cm}$ and Ca125 was highly elevated. Though during laparotomy adnexa were normal macroscopically, pathological examination revealed the presence of a microscopic adenocarcinoma of the fallopian tube (Frings et al. 2005). In a 53-year-old patient with anti-NMDAR encephalitis whose neurologic and psychiatric condition was deteriorating, the decision of abdominal laparoscopy was made in spite of normal abdominal and pelvic CT scan. Though both adnexa were macroscopically normal, the pathologic examination revealed a sex cord tumor (Tanyi et al. 2012). In a group of adult women affected with anti-NMDAR encephalitis, $56 \%$ had ovarian teratoma (Florance et al. 2009). It should be noted that this fraction was significantly lower in adolescents and children $(31 \%)$. Ovarian resection in patients with PNS without clear diagnosis of cancer can be considered effective in terms of both malignancy and neurologic outcome. This can have considerable value in neoplasm therapy, for often the surgery reveals very early stage disease. It is also suggested by some authors that an early management of malignancy may prevent a more severe neurologic deterioration that may remain irreversible and highly debilitating otherwise (Vedeler et al. 2006; Tanyi et al. 2012). It has been confirmed that antitumor treatment improves overall survival in these patients (Shams'ili et al. 2003). In anti-NMDAR encephalitis, an emergent surgery contributes substantially to the final outcome and may enable even almost complete recovery (Dalmau et al. 2007; Florance et al. 2009; Tanyi et al. 2012). Even if serial CT or ultrasound is not suggestive of teratoma, an explorative surgery may prove informative. In a woman affected with anti-NMDAR encephalitis, blind oophorectomy was performed revealing an underlying teratoma and the resection was associated with significant neurological improvement (Johnson et al. 2010). In contrast, an excision of ovaries in combination with immunotherapy led to clinical improvement in another patient, but surprisingly the pathological examination was normal (Parratt et al. 2009). Taken together, it seems reasonable to perform an explorative laparoscopy or laparotomy in patients with paraneoplastic cerebellar syndrome or anti-NMDAR encephalitis whose imaging studies appear normal. After precise exclusion of other neurological aetiologies and considering the patient's age, the salpingo-oophorectomy of macroscopically normal adnexa may appear beneficial.

\section{Summary}

The clinical manifestation of ovarian tumors can be preceded by neurological deficit, particularly in cases with ovarian cancer or teratoma. The detection of onconeural antibodies (e.g., anti-Yo) strongly indicates the presence of ovarian tumor in patients with neurological deficit. If the tumor is not identified, an obligation for systematic screening exists. Surgery and immunomodulatory treatment are considered as the most important management among such a group of patients. 
Acknowledgments We would like to thank Professor Xandra O. Breakefield (Department of Neurology, Massachusetts General Hospital, Harvard Medical School) for fruitful discussions and valuable suggestions on this paper. Mikolaj Piotr Zaborowski is a recipient of a scholarship from the Kosciuszko Foundation.

Conflict of interest The authors have declared that no competing interests exist.

Open Access This article is distributed under the terms of the Creative Commons Attribution License which permits any use, distribution, and reproduction in any medium, provided the original author(s) and the source are credited.

\section{References}

Albert ML, Darnell RB (2004) Paraneoplastic neurological degenerations: keys to tumour immunity. Nat Rev Cancer 4(1):36-44

Albert ML, Darnell JC, Bender A, Francisco LM, Bhardwaj N, Darnell RB (1998) Tumor-specific killer cells in paraneoplastic cerebellar degeneration. Nat Med 4(11):1321-1324

Albert ML, Austin LM, Darnell RB (2000) Detection and treatment of activated $\mathrm{T}$ cells in the cerebrospinal fluid of patients with paraneoplastic cerebellar degeneration. Ann Neurol 47(1):9-17

Anderson NE, Rosenblum MK, Posner JB (1988) Paraneoplastic cerebellar degeneration: clinical-immunological correlations. Ann Neurol 24(4):559-567

Basu S, Alavi A (2008) Role of FDG-PET in the clinical management of paraneoplastic neurological syndrome: detection of the underlying malignancy and the brain PET-MRI correlates. Mol Imaging Biol 10(3):131-137

Brain WR, Daniel PM, Greenfield JG (1951) Subacute cortical cerebellar degeneration and its relation to carcinoma. J Neurol Neurosurg Psychiatry 14(2):59-75

Cao Y, Abbas J, Wu X, Dooley J, van Amburg AL (1999) Anti-Yo positive paraneoplastic cerebellar degeneration associated with ovarian carcinoma: case report and review of the literature. Gynecol Oncol 75(1):178-183

Choi K-D, Kim JS, Park S-H, Kim YK, Kim SE, Smitt PS (2006) Cerebellar hypermetabolism in paraneoplastic cerebellar degeneration. J Neurol Neurosurg Psychiatry 77(4):525-528

Croft PB, Wilkinson M (1965) The incidence of carcinomatous neuromyopathy in patients with various types of carcinoma. Brain $\mathbf{J}$ Neurol 88(3):427-434

Dalmau J, Rosenfeld MR (2008) Paraneoplastic syndromes of the CNS. Lancet Neurol 7(4):327-340

Dalmau J, Tüzün E, Wu H, Masjuan J, Rossi JE, Voloschin A, Baehring JM, Shimazaki H, Koide R, King D, Mason W, Sansing LH, Dichter MA, Rosenfeld MR, Lynch DR (2007) Paraneoplastic anti-N-methyl-D-aspartate receptor encephalitis associated with ovarian teratoma. Ann Neurol 61(1):25-36

Dalmau J, Gleichman AJ, Hughes EG, Rossi JE, Peng X, Lai M, Dessain SK, Rosenfeld MR, Balice-Gordon R, Lynch DR (2008) Anti-NMDA-receptor encephalitis: case series and analysis of the effects of antibodies. Lancet Neurol 7(12):1091-1098

Dalmau J, Lancaster E, Martinez-Hernandez E, Rosenfeld MR, Balice-Gordon R (2011) Clinical experience and laboratory investigations in patients with anti-NMDAR encephalitis. Lancet Neurol 10(1):63-74

Darnell RB, DeAngelis LM (1993) Regression of small-cell lung carcinoma in patients with paraneoplastic neuronal antibodies. Lancet 341(8836):21-22

Darnell RB, Posner JB (2003) Paraneoplastic syndromes involving the nervous system. N Engl J Med 349(16):1543-1554
Darnell JC, Albert ML, Darnell RB (2000) Cdr2, a target antigen of naturally occurring human tumor immunity, is widely expressed in gynecological tumors. Cancer Res 60(8):2136-2139

Drlicek M, Bianchi G, Bogliun G, Casati B, Grisold W, Kolig C, Liszka-Setinek U, Marzorati L, Wondrusch E, Cavaletti G (1997) Antibodies of the anti-Yo and anti-Ri type in the absence of paraneoplastic neurological syndromes: a long-term survey of ovarian cancer patients. J Neurol 244(2):85-89

Eichler TW, Totland C, Haugen M, Qvale TH, Mazengia K, Storstein A, Haukanes BI, Vedeler CA (2013) CDR2L Antibodies: a new player in paraneoplastic cerebellar degeneration. ed. Prasun Datta. PloS one 8(6):e66002

Florance NR, Davis RL, Lam C, Szperka C, Zhou L, Ahmad S, Campen CJ, Moss H, Peter N, Gleichman AJ, Glaser CA, Lynch DR, Rosenfeld MR, Dalmau J (2009) Anti-N-methyl-D-aspartate receptor (NMDAR) encephalitis in children and adolescents. Ann Neurol 66(1):11-18

Forgy AP, Ewing TL, Flaningam J (2001) Two paraneoplastic syndromes in a patient with ovarian cancer: nephrotic syndrome and paraneoplastic cerebellar degeneration. Gynecol Oncol 80(1):96-98

Frings M, Antoch G, Knorn P, Freudenberg L, Bier U, Timmann D, Maschke M (2005) Strategies in detection of the primary tumour in anti-Yo associated paraneoplastic cerebellar degeneration. J Neurol 252(2):197-201

Giometto B, Grisold W, Vitaliani R, Graus F, Honnorat J, Bertolini G (2010) Paraneoplastic neurologic syndrome in the PNS Euronetwork database: a European study from 20 centers. Arch Neurol 67(3):330-335

Goldstein BH, Birk CL, Van Houten M, Veve R, Brown JV, Rettenmaier MA, Micha JP (2009) Ovarian cancer and late onset paraneoplastic cerebellar degeneration. Arch Gynecol Obstet 280(1):99-101

Graus F, Dalmou J, Rene R, Tora M, Malats N, Verschuuren JJ, Cardenal F, Vinolas N, del Muro JG, Vadell C, Mason WP, Rosell R, Posner JB, Real FX (1997) Anti-hu antibodies in patients with small-cell lung cancer: association with complete response to therapy and improved survival. J Clin Oncol 15(8):2866-2872

Graus F, Delattre JY, Antoine JC, Dalmau J, Giometto B, Grisold W, Honnorat J, Smitt PS, Vedeler C, Verschuuren JJ, Vincent A, Voltz R (2004) Recommended diagnostic criteria for paraneoplastic neurological syndromes. J Neurol Neurosurg Psychiatry 75(8):1135-1140

Greenlee JE, Lipton HL (1986) Anticerebellar antibodies in serum and cerebrospinal fluid of a patient with oat cell carcinoma of the lung and paraneoplastic cerebellar degeneration. Ann Neurol 19(1):82-85

Hetzel DJ, Stanhope CR, O’Neill BP, Lennon VA (1990) Gynecologic cancer in patients with subacute cerebellar degeneration predicted by anti-purkinje cell antibodies and limited in metastatic volume. Mayo Clin Proc 65(12):1558-1563

Johnson N, Henry C, Fessler AJ, Dalmau J (2010) Anti-NMDA receptor encephalitis causing prolonged nonconvulsive status epilepticus. Neurology 75(16):1480-1482

Kumar MA, Jain A, Dechant VE, Saito T, Rafael T, Aizawa H, Dysart KC, Katayama T, Ito Y, Araki N, Abe T, Balice-Gordon R, Dalmau J (2010) Anti-N-methyl-D-aspartate receptor encephalitis during pregnancy. Arch Neurol 67(7):884-887

Mangler M, de Perez IT, Teegen B, Stöcker W, Prüss H, Meisel A, Schneider A, Vasiljeva J, Speiser D (2013) Seroprevalence of anti-N-methyl-D-aspartate receptor antibodies in women with ovarian teratoma. J Neurol 260(11):2831-2835

Manley GT, Smitt PS, Dalmau J, Posner JB (1995) Hu antigens: reactivity with $\mathrm{Hu}$ antibodies, tumor expression, and major immunogenic sites. Ann Neurol 38(1):102-110

Marchand V, Graveleau J, Lanctin-Garcia C, Bourbouloux E, Bridji B, Resche I, Kraeber-Bodéré F, Rousseau C (2007) A rare 
gynecological case of paraneoplastic cerebellar degeneration discovered by FDG-PET. Gynecol Oncol 105(2):545-547

Mason WP, Dalmau J, Curtin JP, Posner JB (1997) Normalization of the tumor marker CA-125 after oophorectomy in a patient with paraneoplastic cerebellar degeneration without detectable cancer. Gynecol Oncol 65(1):173-176

Mathew RM, Cohen AB, Galetta SL, Alavi A, Dalmau J (2006) Paraneoplastic cerebellar degeneration: Yo-expressing tumor revealed after a 5-year follow-up with FDG-PET. J Neurol Sci 250(1-2):153-155

Michalak S (2008) The pathomechanisms of cerebellar degeneration in the course of experimental neoplastic disease in rat. Poznan University of Medical Sciences, Poznan

Michalak S, Kossut A, Szpurek D, Krygowska J, Sajdak S, Kozubski W (2010) Neurological paraneoplastic syndromes among women in western Poland: a study focused on ovarian tumors. NeuroOncology 12(Suppl 3):59-60

Monstad SE, Storstein A, Dørum A, Knudsen A, Lønning PE, Salvesen HB, Aarseth JH, Vedeler CA (2006) Yo antibodies in ovarian and breast cancer patients detected by a sensitive immunoprecipitation technique. Clin Exp Immunol 144(1):53-58

Monstad SE, Drivsholm L, Skeie GO, Aarseth JH, Vedeler CA (2008) CRMP5 antibodies in patients with small-cell lung cancer or thymoma. Cancer Immunol Immunother CII 57(2):227-232

Negishi Y, Sakai K, Noguchi Y, Iwasaki N, Kawai N (2013) Paraneoplastic cerebellar degeneration caused by ovarian clear-cell carcinoma. J Obstet Gynaecol Res 40(2):614-617

Okano HJ, Park WY, Corradi JP, Darnell RB (1999) The cytoplasmic purkinje onconeural antigen $\mathrm{Cdr} 2$ down-regulates c-Myc function: implications for neuronal and tumor cell survival. Genes Dev 13(16):2087-2097

Parratt KL, Allan M, Lewis SJG, Dalmau J, Halmagyi GM, Spies JM (2009) Acute psychiatric illness in a young woman: an unusual form of encephalitis. Med J Aust 191(5):284-286

Peterson K, Rosenblum MK, Kotanides H, Posner JB (1992) Paraneoplastic cerebellar degeneration. I. A clinical analysis of 55 antiYo antibody-positive patients. Neurology 42(10):1931-1937

Rees JH (2004) Paraneoplastic syndromes: when to suspect, how to confirm, and how to manage. J Neurol Neurosurg Psychiatry 75(Suppl 2):ii43-ii50

Rojas I, Graus F, Keime-Guibert F, Reñé R, Delattre JY, Ramón JM, Dalmau J, Posner JB (2000) Long-term clinical outcome of paraneoplastic cerebellar degeneration and anti-Yo antibodies. Neurology 55(5):713-715

Rubello D, Vitaliani R, Rigoni MT, Rampin L, Giometto B, Casara D, Zonzin GC, Zavagno G, Capirci C, Shapiro B, Muzzio PC (2005) A rare case of paraneoplastic cerebellar degeneration discovered by whole-body F-18 FDG PET. Clin Nucl Med 30(10):704-706

Russo AE, Scalone S, Leonardi GC, Scalisi A, Giorda G, Sorio R (2013) Paraneoplastic cerebellar degeneration associated with ovarian cancer. Oncol Lett 5(2):681-683

Shams'ili S, Grefkens J, de Leeuw B, van den Bent M, Hooijkaas H, van der Holt B, Vecht C, Smitt PS (2003) Paraneoplastic cerebellar degeneration associated with antineuronal antibodies: analysis of 50 patients. Brain J Neurol 126(Pt 6):1409-1418
Stefens-Stawna P, Piorunek T, Gabryel-Batura H, Kozubski W, Michalak S (2013) Neurological paraneoplastic syndromes in lung cancer patients. Adv Exp Med Biol 756:333-339

Szubert S, Michalak S, Szpurek D, Moszynski R, Krygowska-Zielinska J, Sajdak S (2012) Anti-ovarian antibodies in sera of patients with ovarian tumors. Immunol Lett 148(2):133-137

Tanaka M, Tanaka K (1996) HLA A24 in paraneoplastic cerebellar degeneration with anti-Yo antibody. Neurology 47(2):606-607

Tanaka K, Tanaka M, Onodera O, Igarashi S, Miyatake T, Tsuji S (1994) Passive transfer and active immunization with the recombinant leucine-zipper (Yo) protein as an attempt to establish an animal model of paraneoplastic cerebellar degeneration. J Neurol Sci 127(2):153-158

Tanaka M, Tanaka K, Onodera O, Tsuji S (1995) Trial to establish an animal model of paraneoplastic cerebellar degeneration with antiYo antibody. 1. Mouse strains bearing different MHC molecules produce antibodies on immunization with recombinant Yo protein, but do not cause purkinje cell loss. Clin Neurol Neurosurg 97(1):95-100

Tanaka M, Tanaka K, Shinozawa K, Idezuka J, Tsuji S (1998) Cytotoxic $\mathrm{T}$ cells react with recombinant Yo protein from a patient with paraneoplastic cerebellar degeneration and anti-Yo antibody. J Neurol Sci 161(1):88-90

Tanyi JL, Marsh EB, Dalmau J, Chu CS (2012) Reversible paraneoplastic encephalitis in three patients with ovarian neoplasms. Acta Obstet Gynecol Scand 91(5):630-634

Titulaer MJ, Soffietti R, Dalmau J, Gilhus NE, Giometto B, Graus F, Grisold W, Honnorat J, Sillevis Smitt PAE, Tanasescu R, Vedeler CA, Voltz R, Verschuuren JJGM (2011) Screening for tumours in paraneoplastic syndromes: report of an EFNS task force. Eur J Neurol 18(1):19-e3

Totland C, Aarskog NK, Eichler TW, Haugen M, Nostbakken JK, Monstad SE, Salvesen HB, Mork S, Haukanes BI, Vedeler CA (2011) CDR2 antigen and Yo antibodies. Cancer Immunol Immunother 60(2):283-289

Tüzün E, Zhou L, Baehring JM, Bannykh S, Rosenfeld MR, Dalmau J (2009) Evidence for antibody-mediated pathogenesis in AntiNMDAR encephalitis associated with ovarian teratoma. Acta Neuropathol 118(6):737-743

Vedeler CA, Antoine JC, Giometto B, Graus F, Grisold W, Hart IK, Honnorat J, Sillevis Smitt PAE, Verschuuren JJGM, Voltz R (2006) Management of paraneoplastic neurological syndromes: report of an EFNS task force. Eur J Neurol 13(7):682-690

Vitaliani R, Mason W, Ances B, Zwerdling T, Jiang Z, Dalmau J (2005) Paraneoplastic encephalitis, psychiatric symptoms, and hypoventilation in ovarian teratoma. Ann Neurol 58(4):594-604

Zaborowski MP, Michalak S (2013) Cell-mediated immune responses in paraneoplastic neurological syndromes. Clin Dev Immunol 2013:630602

Zuliani L, Graus F, Giometto B, Bien C, Vincent A (2012) Central nervous system neuronal surface antibody associated syndromes: review and guidelines for recognition. J Neurol Neurosurg Psychiatry 83(6):638-645 